\title{
Palakesi obiugri mütoloogiast IV
}

Aado Lintrop

Ülevaate lõpetuseks tutvustan tegelast, kellest rääkides kasutatakse tavaliselt vaid eufemisme (mansidel näiteks ui 'loom', n'urumui 'sooloom', untvoi 'metsloom', liling ui 'elav loom', jalpõng ui 'püha loom', ans'õhh 'vana', maakolang oika 'muldkoja taat', konsõng oika 'küüneline taat', pupi/pupak(ve), viimane peamiselt naiste ja laste pruugis), ning kes on kujunenud peamiseks obiugrilaste pärimust koondavaks ja alal hoidvaks teguriks. Tema nimel anti vandeid, siiralt uskudes, et valetajat tabab kiire karistus ta käppade vahel, tema auks korraldati kõige suuremaid pidustusi. Mitte ühelegi ülikule ega jumalusele ei esitatud nii palju laule ja tantse kui talle. Isegi ta kehaosi ei nimetatud õigete nimedega. Kõrv oli aankval 'känd', silm sov 'täht' või sosõg 'mustsõstar', nina seenõg 'kasepahk', keel khoosvoi 'sipelgas', kõht khaap 'paat' jne.

Karu. Mõnedes karupeielauludes esineb karu taevajumala Numi-Toorumi lapsena (pojana või tütrena), kes isa keelust hoolimata kodust välja läheb. Näiteks on mansi müütilises laulus värsid:

Ta pääses välja, kuulis:

linnaserva poolt kosab hääli.

Ta kuulis: palju rahvast on näha.

Mängiv mees mängib.

Üks ratsanik hakkas teda taga ajama, ta pages tagasi.

Tagasipagemise ajal ta jalg läbi vajus.

Ta pöördus tagasi, vaatas alla:

otsekui kollase matiga kaetud maa paistab.

Mõtleb: "Minusuguse metsloomatüdruku

ringi kõndimiseks milline maake!"

(Kannisto, Liimola 1958: 35-36)

Ning tütar palus isa, et see ta maa peale laseks. Isa aga vastas:

"Tütreke, milline tore maa!

Sinna maale kui satud,

paksud sääseparved, paksud parmuparved sulle piina teevad.

Nina ei mahu (pistma), kõrv(a) ei mahu (pistma), tihe (metsa)küngas."

(Samas: 38-39.)

Ent tütar tahtis ikka maa peale.

Isa läks seitsme maja nurka,

hakkas raudhälli tegema.

Tegi seda, lõpetas.

Pani tütre hälli istuma.

Kuldrõngastega rõngasketi helina kõlades lasti ta alla.

Palju lasti alla või vähe lasti, seal hoiti.

Vaatas alla - sama kaugel,

vaatas üles - sama kaugel.

Ta isa tugeva külmaninalise ninatuule avas:

põhjamere põhjani ta kandus, lõunavee allikateni ta kandus. (1)

Isa hakkas teda üles tirima.

Tiris üles. Isa hakkas küsima:

"No kuidas oli, tütreke?

Kas oli külmaninalise ninatuule vägi suur?"

Seepärast ütlen seda -

sel maal on sul paha elada, ei sobi (sulle), piinlema hakkad.

Tütreke, kas ikka tahad?"

Jah, isa, lase mind alla!"

(Samas: 39-40.) 
Maa peal on sood ja tihedad padrikud, sääsed piinavad, süüa pole. Karutüdruk satub surnuaiale, pöörab hauad segamini ja sööb laipu, käib ka jahimehe aida juures ja lõhub selle ning rüüstab püünised. Ta jääb järjest jõuetumaks. Oma tädilt emajäneselt (Kaltesh-eekva zoomorfne kuju!) küsib ta, miks on väetiks jäänud. Too ütleb, et surnute rahu rikkumine ja laipade söömine on seda teinud. Marju tuleb süüa, õpetab ta karu. Ka emaahm räägib sama juttu. Viimaks hakkabki karutüdruk marju sööma ja läheb neist rasva. Talveks heidab ta koopasse magama. Tulevad jahimehed, tapavad ta ja viivad külla. (Samas: 41-50.)

Teises mansi karulaulus manitseb isa tütart:

"Lapseke, alla jõudes inimese haudu, jää sees olevaid surnuid ära puutu, lumes olevaid surnuid ära puutu!

Seitsemenurgelise metsa sees olevat heledat aita, püha aita ära puutu!"

Suure raua helina kõlades, väikese raua helina kõlades lasti ta alla.

Alla ta jõudis. Hällist välja ronis.

Astus siia- tüma, astus sinna - tüma.

Otse vesise soo keskele oli ta lastud.

(Great Bear: 15, minu tõlge mansikeelsest tekstist.)

Esitatud näidetes on karu hellitatud ja sõnakuulmatu lapse rollis, kes saavutab oma tahtmise, kuid jääb ilma kõikvõimsa isa soosingust. Taevajumal ei hakka kehtivat maailmakorda ühe jonnaka lapse pärast muutma, sääsed ja parmud, külm talvine tuul ja läbipääsmatud tihnikud ning tümad sood viivad looma nii kaugele, et ta unustab kõik keelud. Ja kuna ta osutub väljaspool seadust olevaks, on inimesel õigus teda tappa. Sellistes lauludes meenutab karu langenud inglit. Tuletame meelde, et ka allilma valitseja esineb mansi folklooris taevajumala jonnaka pojana (vt artikli eelmist osa), kelle isa lõpuks taevast alla heidab. Samas on karu taevast päritolu tulnukas, keda inimesed vastu võtavad ja kostitavad kui kallist külalist, sest ta pole mitte alatiseks oma taevase isa juurest pagendatud, vaid läheb sinna tagasi. Karu tapmine on ta jumaliku seisundi taastamine. Olles maa peale lastud, pääseb ta isa juurde tagasi vaid maise keha surmamise kaudu.

Ent mitte kõigis karulauludes ei riku karu seadust. Näiteks algab üks Steinitzi kogutud handi karulaul nii:

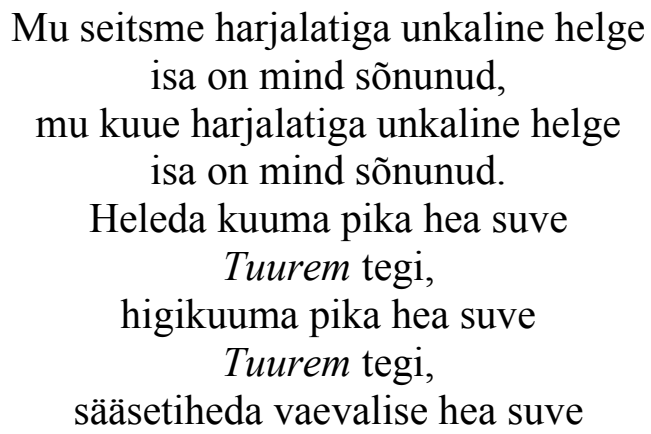

Mu seitsme harjalatiga unkaline helge isa on mind sõnunud. kuuma pika hea suve uma pika hea suve sääsetiheda vaevalise hea suve

\author{
Tuurem tegi, \\ parmutiheda piinalise suve \\ Tuurem tegi. \\ Varesenokaga paljudes soodes \\ mina, loom, astun, \\ harakanokalistes paljudes soodes \\ mina, loom, astun. \\ (Steinitz 1939: 309-310.)
}

Selles laulus toitub karu ilusasti marjadest ning teeb endale sügisel koopa. Sellest hoolimata tuleb jahimees - Hiirekõrgune Väike Isand. Pärast karu tapmist järgneb karulaulule tüüpiline tekst sellest, kuidas täidetakse mitmesugused karujahiga seotud kombed: 


\author{
Emakaru kui olen - \\ mul olevad neli emakaru nööpi \\ taevasse karjudes tehke lahti, \\ taevasse hüüdes tehke lahti; \\ isakaru kui olen - \\ mu viis isakaru nööpi \\ taevasse karjudes lahti tehakse, \\ taevasse hüüdes lahti tehakse.
}

(Samas: 317.)

Karu pannakse sjopõr-hõbeda, kaam-hõbedaga täidetud hälli ning viiakse saja majaga külla.

Küla täitvad paljud mehed

seitsmekordset korduvat kisa nüüd seal kisavad:

"Laiapihalist soo-metslooma nüüd me toome!"

Seejärel

hanejalgkõrgele heale lauale mind, looma, pannakse istuma, paljude heade ohvrikaussidega mind, looma, kostitatakse, paljude heade ohvritaldrikutega mind, looma, kostitatakse.

Palju häid tantsumehi nüüd seal tantsib,

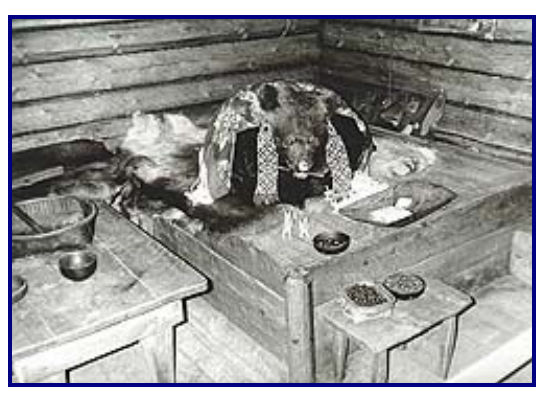

palju häid tantsunaisi nüüd seal tantsib.

(Samas: 318-319.)

Karupeo nurk Hantõ-Mansiiski muиseumis. Foto A. Lintrop 1990.

Karu nööpide avamine ja vajaliku arvu hüüete hüüdmine kuuluvad lahutamatult karu tapmisele järgnevate toimingute hulka, nagu ka kõigi juuresviibijate veega kastmine või lumega loopimine enne karupea pidumajja viimist. Seda kommet tsiteeritud laulus ei mainita, kuid tavaliselt esineb see vihmamängu või veemänguna:

\author{
Inimesele kuuluva \\ pilvepea kõrguse maja, pilvepea sarnase maja \\ ukseavani jõudsid. \\ Lumemängu mängiti, \\ vihmamängu mängiti. \\ (Kannisto, Liimola 1951: 259.)
}

Viimane katkend on võetud Sosva äärest pärit karuga seotud muistendisse põimitud laulust. Muuseas kirjeldatakse seal karupidu nõnda: 


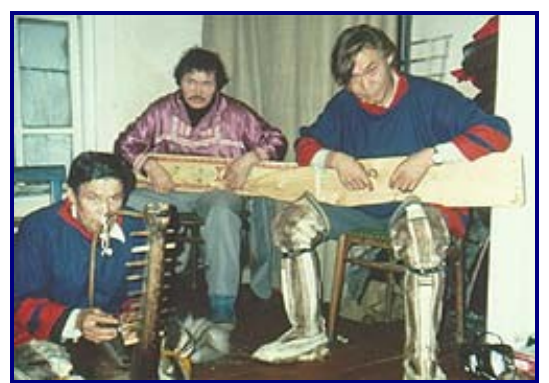

Pillimehed handi karupeietel Juilskis. Foto A. Lintrop 1991.
Vaimude määratud kolm ööd, jumala määratud neli ööd mängiti. Palju selgapainutavaid mehi sisenes, palju rindapainutavaid mehi sisenes. Viiekeelelise keelepuu Linna Isanda-taat võttis kätte. Alumist keelt helistades kõikjal asuvaid tiivulisi jumalaid kõiki ta kohale kutsus. Ülemist keelt helistades

kõikjal asuvaid jalalisi jumalaid kõiki ta kohale kutsus.

(Samas: 260.)

Viiekeelne keelepuu on obiugrilaste kandlesarnane pill (mansi k. sankvaltap), mille saatel tavaliselt tantsitakse, ent millel mängitakse ka jumaluste-haldjate kutsumisviise. Karupeiete laulud jagunevad kolme rühma: karulaulud (mansi uieerõg), etenduslaulud (mansi tuulõglap) ja jumaluste kutsumisning esitluslaulud (mansi kaastaneerõg, pupõg eerõg). Karulauludeks nimetatud laule esitatakse peopäeva esimeses osas ning neis on juttu karu maa peale laskmisest, elust metsas ning jahimehe tulekust ning karu surmamisest, kusjuures jahimeesteks on tavaliselt erinevad mütoloogilised olendid. Laule esitatakse mitmekesi rivis seistes, kätest kinni hoides ja ülakeha koogutades, kusjuures esitajad kannavad spetsiaalseid peakatteid, kindaid ja kitleid. Etenduslaulud on sellised laulud, mida kantakse ette peopäeva keskmises osas, kusjuures esitajad kannavad maske. Osa tegevust antakse edasi proosatekstis dialoogide, pantomiimi ja tantsuga - ühesõnaga näitemänguga. Sageli on etenduslaulud koomilise sisuga.
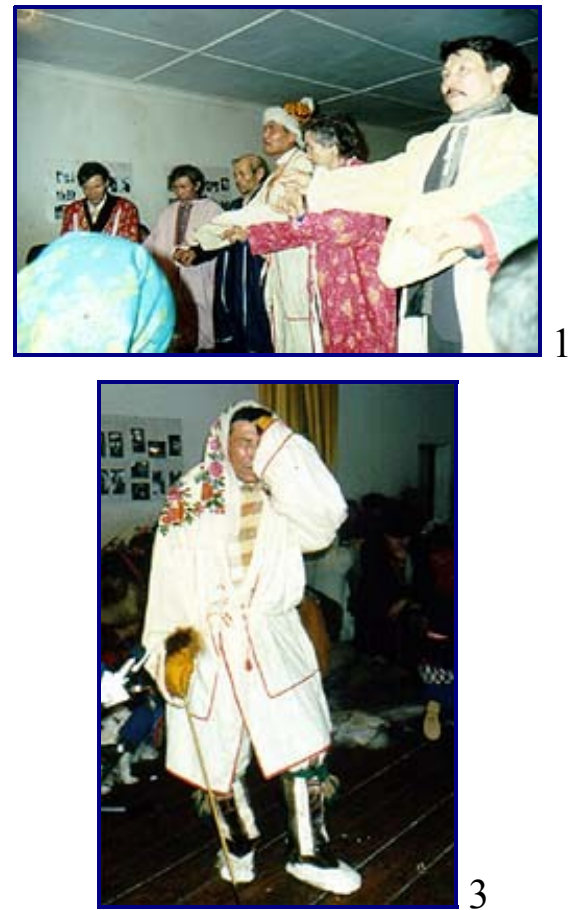

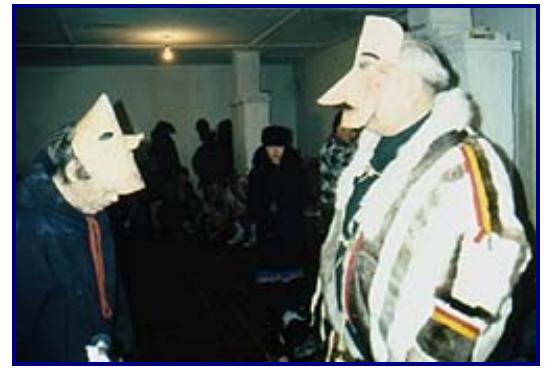

Pilte Juilski karupeietelt.

1. Karulaulu laulmine

2. Etenduslaul

3. Kutsumislaulu esitamine

Fotod ja video A. Lintrop 1991.

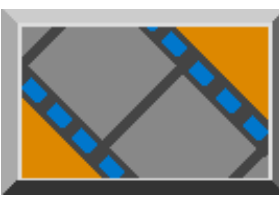

Karulaul 1.1 Mb.mpg video

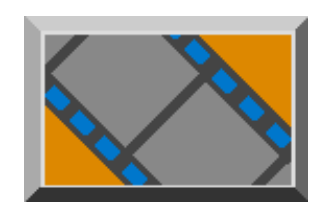

Etenduslaul 1.2 Mb .mpg video

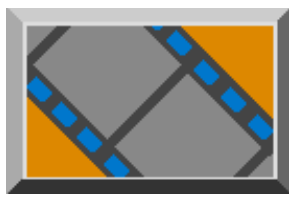

Tants $1.1 \mathrm{Mb} . \mathrm{mpg}$ video

Haldjate-jumaluste kutsumislaule lauldakse peopäeva viimases osas enamasti üksi ja osaliselt kaetud näoga. Neid võiks nimetada ka esitluslauludeks, sest tüüpiliselt on nende sisu selline - mina, haldjas või haldjatar (nii mansid kui handid nimetavad erinevast soost üleloomulikke olendeid eri 
nimedega) olen oma isa Numi-Toorumi poolt taevast alla lastud või elama määratud sellisesse ja sellisesse paika, mind tuntakse nii- ja naasuguste nimede all (need eufemistlikud nimed sisaldavad mõnikord informatsiooni üleloomuliku olendi ülesannete ja tegevuse kohta); määratud paigas elades kuulsin oma valvsa kõrvaga, et seal ja seal peetakse laiapihalise soo-metslooma auks pidu, panin selga nii- ja naasugused rõivad ja asusin sel või teisel kombel teele. Jumaluse pidumajja jõudmist kirjeldab Kazõmi haldjatari kutsumislaul (handi) näiteks nii:

\author{
Muinasmehe poja ehitatud \\ lehisepuust tehtud ukse \\ kuusepuust tehtud ukse \\ oma viiesõrmelise sõrmekäega \\ mina, haldjatar, avan. \\ Väikeste poiste lärmilisse majja, \\ väikeste tüdrukute lustilisse majja, \\ mina, haldjatar, astun. \\ Taelatule ja koprarasvaste kätega(2) \\ mind, haldjatari, vastu võeti. \\ "Minu paljud majas istuvad naised, \\ minu paljud majas istuvad mehed! \\ Väikeste tüdrukute ea terviseks \\ teie nüüd istute, \\ väikeste poiste ea terviseks \\ teie nüüd istute! \\ Viiekeelse keelepuu \\ alumist keelt kui helistatakse,
}

\author{
alumiste vaimude viisihääl \\ seal võib kõlada; \\ ülemist keelt kui helistatakse, \\ ülemiste vaimude viisihääl \\ seal võis kõlada. \\ Mida ma saan teil teha lasta? \\ Veekalaõnne tantsu, \\ teil lasen (tantsida). \\ metsloomaõnne tantsu \\ teil lasen (tantsida).(3) \\ Pärast minu äraminekut \\ teid ründavat hukutavat suurt \\ püha tõbe ärgu olgu. \\ Sülelise kasuka süles \\ ennast et kaitseksite, \\ varrukalise kasuka varrukas \\ ennast et kaitseksite.(4) \\ (Steinitz 1939: 368-369.)
}

Obiugrilaste karupeied on omapärane institutsioon pärimuse säilitamiseks ja edasiandmiseks. Pidumajja saabuv laiapihaline soo-metsloom on otsekui visitatsiooni sooritav piiskop, kelle ees nii inimesed kui üleloomulikud olendid üles peavad astuma. Seepärast saabuvadki pidumajja paljud haldjad ja jumalused, kes lauljate suu läbi räägivad oma päritolust, elupaigast ja tegemistest. Sellepärast peetakse laulude üle ranget arvestust, ja kui mõni kohustuslik laul ununeb, tuleb pidu kas ära jätta või kutsuda külla keegi, kes vajalikku laulu mäletab. Ning sellepärast on karupeiete laulud nii konkreetsed, sisaldades palju usundi ja kombestiku alast informatsiooni. Näiteks võib tuua veel katkendid Sosva-äärsetelt mansidelt kogutud karupeo lõpulaulust, sealse rahva pühast laulust (selle lõpuosa ei tohtinud naised ja lapsed kuulda):

Inimese nõgise maja nurka laskusin, inimese nõgise maja nurka olen istuma pandud.

Peenest kalevist külluslikku pessa olen istuma pandud, peenest siidist külluslikku pessa olen istuma pandud.

Taelatulesuitsuste kätega

öösel mu juurde tullakse, päeval mu juurde tullakse.

Lõputut tüdrukute lusti mulle näidatakse, lõputut poiste lusti mulle näidatakse.

Lõputu järvetoiduga mind küllastatakse, lõputu obitoiduga mind küllastatakse.

Järverasvase hea käega, obirasvase hea käega mu ettepoole turritavad karvaotsad tagasi silitatakse, mu tahapoole turritavad karvaotsad ettepoole silitatakse.

Lõputut tüdrukute lusti vaatan, lõputut poiste lusti vaatan.

Sel ajal, kui ma niimoodi vaatasin, paljaste kätega tüdrukud mulle tantsisid, paljaste kätega poisid mulle tantsisid, mu kuldse meele ots, mu kõhuka naise kõht vette kukkus, metsa kukkus.

(Kannisto, Liimola 1958: 366-367.) 
Et eelnev visitatsiooni-jutt pole õhust võetud, seda tunnistab ka esitatud katkendi lõpp, kus karu pahandab selle pärast, et talle paljakäsi tantsitakse. Teatavasti peavad karupeo tantsijad-lauljad kandma kindaid. Järgnevalt kirjeldatakse laulus seda, kuidas pidumajast välja kukkunud karu hakkab majast eemaldudes kasvama - esimesel ööl on ta veel maja lähedal ja hiire suurune, teisel ööl naiste lumetoomise tee lõpus kärbi suurune, kolmandal ööl meeste oravaküttimise raja lõpus ahmi suurune, seejärel aga juba karu suurune. Siis valmistab ta endale seljapikkuse tohtpauna:

Tohuse kase tohtu koorisin,

Seljakõrguse pika koti tegin.

$\mathrm{Mu}$ inimlapsed

järvetoituga olid mind küllastanud,

obitoiduga olid mind küllastanud.

Seljakõrgusesse pikka kotti

järvetoidu panin,

obitoidu panin.

Peene kaleviga olid nad mind küllastanud,

peene siidiga olid nad mind küllastanud.

Peene kalevi kotti panin,

peene siidi kotti panin...

(Samas: 374-375.)

Karu võtab koti selga ja alustab teed isakoju. Teel kohtab ta metshiide ja teisi üleloomulikke olendeid, kes temaga lugupidamatult käituvad:

Seljakõrguse pika koti üles tõstan, kerekõrguse pika koti üles tõstan.

Paunselgse mäehiiuna astun, paunselgse metshiiuna astun.

Põlvinitallatud sügavat rada astun, õlunitallatud sügavat rada astun.

jõuan metshiiuteiba juurde, mille otsa pole näha, jõuan vaimuteiba juurde, mille lõppu pole näha.

Väikese hambavahevilega vilistati mind, selgatabava vägeva naeruga naerdi mind, rindatabava vägeva naeruga naerdi mind:

"Meie inimese majja laskunud naine on tagasi!"
Nad naersid omakeskis:

"Vaata sinna!

ta luude vahel on urgitsetud,

ta liha vahel on urgitsetud, ainult luukere on järele jäänud!"

Seda kuulates

oma südamliku naise südant kuulan:

lehisepuine tugev ora torkab,

kuusepuine tugev ora torkab.

$\mathrm{Mu}$ vetteläinud meel läks vette, mu metsaläinud meel läks metsa.

(Samas: 375-377.)

Nii, nagu inimesi, nõnda ähvardab karu ka metshiide nende üleastumiste pärast karistada. Viimaks jõuab ta koju:

Kaua käisin või vähe käisin,

Numi-Toorumi, oma isakese,

Numi-Toorumi, oma taadikese

kuldse maja ukse ju avasin,

kuldsesse majja sisse astusin.

Paunselgse mäehiiuna sisse astusin, paunselgse metshiiuna sisse astusin, oma isakese sooblinahksele põlvele,

karusnahksele põlvele istusin.

Isake ütleb:

"Inimese majja laskunud tütreke, oledki tagasi."

"Olengi tagasi."

Seljakõrgusest pikast kotist ammutasin isakese paljudele noolepoegadele, paljudele vibupoegadele piisavalt kalevit igaühele jagasin, piisavalt siidi igaühele jagasin.

Mu isa ütles:

"Inimese elumaja nurka sa laskusid.

Kuidas sind koheldi?"

(Samas: 382-383.) 
Seepeale loeb karu üles kõik need seigad, mis teda pahandasid nii inimeste juures kui koduteel. Ta palub isal süüdlasi karistada. Ent Numi-Toorum vabandab süüdlased välja rumalusega. Ta ütleb, et kõik nad tema poolt sellisteks loodud ning seepärast pole neid vaja nuhelda. Obiugri metshiide menkve (nagu paljusid teisi metsaga seotud üleloomulikke olendeid Põhja-Euraasia rahvaste usundeis) iseloomustatakse tõepoolest üsna rumalatena. Samas annab laul mõista, et täie mõistusega olendite jaoks oleksid eksimustel kurvad tagajärjed.

Karuga seoses võime rääkida ka totemistlikest motiividest. Obiugrilaste seas üldiselt tuntud muistendi kohaselt on kogu por-fraatria teke aga seotud mos'-naise ja karuga (vt. Sokolova 1987: 119, Schmidt 1989: 195, 202-203). Selle muistendi Tshernetsovi poolt kokkuvõtlikult esitatud varianti on tsiteerinud paljud erinevad teadlased. Jutt koosneb kahest osast, mille seob üheks tervikuks karuputk. Esimeses osas on tegelasteks õde ja vend. Õde hävitab puunuku, mille vend endale naiseks on teinud ja heidab ise nuku asemele. Vend elab enese teadmata oma õega nagu naisega. Neil sünnib laps, kes intsesti paljastab. Vend tapab õe (variantides ka poja) ja läheb inimesi otsima. Sellega esimene osa lõpeb. Ent õe verest (variantides kõdunenud lihast ja luust) kasvab karuputk, mida söönud karu jääb tiineks ja sünnitab kaks kutsikat ning inimtüdruku. Loo teine osa meenutab suuresti karulaulu (variantides ongi sellesse põimitud laul), eriti seda osa, milles on juttu karu talveunest, tapmisest, külla viimisest ja karupeost. Karuema näeb sündmusi ette ning laseb tütrel teha ettevalmistusi selleks, et jahimees teda koos karudega ei tapaks. Inimtüdruk pääsebki eluga, ta viiakse ühes tapetud karudega külla. Seal peetakse pidu, öösel aga kurdavad karud tüdrukule, et neil on üks või teine kehaosa puudu. Tüdruk viib neile puuduolevad kohad ning karud lähevad iga ööga järjest kaugemale. Viimaks saab neist Väikese vankri tähtkuju. (Kannisto, Liimola 1951: 250-263.) Inimtüdrukust aga saanud alguse kõik por-inimesed. (Tshernetsov 1968: 108-109.) Muistendi Sosva-äärsetelt mansidelt kogutud varianti loe ajakirja muinasjutu-osas.

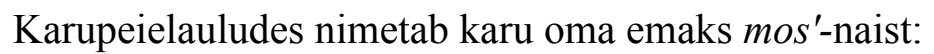

$$
\begin{gathered}
\text { ühel pool oleva käpakese } \\
\text { mos'-naise, mu ema õmmeldud } \\
\text { kümnetükilise kirju lina kombel } \\
\text { alla laotasin, } \\
\text { teise poole käpakese } \\
\text { mos'-naise, mu ema õmmeldud } \\
\text { kaelast lõigatud karusnahkse teki kombel } \\
\text { ülle tõmbasin. } \\
\text { (Kannisto, Liimola 1958: 153) }
\end{gathered}
$$

Sõgva mansidelt pärit variandi kohaselt muutub karuks üksi elava mos'-naise poeg, keda ema ei luba kodust kaugele mängima minna. Poiss ei kuula sõna ja ühel hetkel põgenevad kõik külalapsed ta eest, karjudes: "Mos'-naise poeg tuleb!" Karuks muutunud poiss ründab ema ja läheb ta keelust hoolimata metsa (Schmidt 1989: 195). Ent mos'-naine osutub nii mansi kui handi juttudes sageli Kalteshiks. Sellega jõuame jälle taevaliste juurde tagasi.

\section{Viidatud kirjandus:}

Great Bear = The Great Bear. A Thematic Anthology of Oral Poetry in the Finno-Ugrian languages. Pieksamäki 1993.

Kannisto, Liimola 1951 = Kannisto, A., Liimola, M. Wogulische Volksdichtung I. Texte mytischen Inhalts. Suomalais-Ugrilaisen Seuran Toimituksia 101. Helsinki.

Kannisto, Liimola 1958 = Kannisto, A., Liimola, M. Wogulische Volksdichtung IV. Bärenlieder. 
Suomalais-Ugrilaisen Seuran Toimituksia 114. Helsinki 1958.

Schmidt 1989 = Schmidt, É. Bear Cult and Mythology of the Northern Ob-Ugrians. Uralic Mythology and Folklore. Budapest, pp 187-232.

Sokolova 1987 = Sokolova Z. P. K proishozhdeniju obskih ugrov i ih fratrii (po dannõm folklora). Traditsionnõje verovanija i bõt narodov Sibiri XIX natshalo XX v. Novosibirsk, s. 118-133. Steinitz 1939 = Steinitz, W. Ostjakische Volksdichtung und Erzählungen aus Zwei Dialekten. 1. Teil. Õpetatud Eesti Seltsi Toimetused XXXI. Tartu.

Tshernetsov 1968 = Tshernetsov V. Perioditsheskie obrjadõ $i$ tseremonii u obskih ugrov, svjazannõje s medvedem. Congressus Secundus Internationalis Fenno-Ugristarum, Helsingiae habitus 23. -28. VIII 1965. Pars II. Acta Ethnologica. Helsinki, s. 102-111.

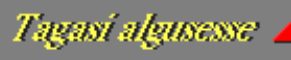

1. Karu kiigub põhja-lõuna suunas ühest maailma servast teiseni.

2. Nagu eespool juba mainitud, tehti karupeietel taelasuitsu, millega puhastati kogu peomaja ja seal viibivaid inimesi. Koprarasv sümboliseerib ilmselt lihtsalt külluslikust söögist rasvaseid käsi, vrd. mansi laulu värsse: Taelatulesuitsuste kätega/ öösel mu juurde tullakse, päeval mu juurde tullakse. - Järverasvase hea käega,/ obirasvase hea käega/ mu ettepoole turritavad karvaotsad/ tagasi silitatakse... (Kannisto, Liimola 1958: 366-367, värsid 6-7, 12-13, vt. allpool.)

3. Neis värssides väljendub karupeo üks eesmärke - jahi- ja kalaõnne tagamine.

4. Ja neis värssides püüdlus tagada jumaluste kaitse haiguste vastu. Tuleb märkida, et karupidu sarnaneb mõneti shamaanirituaaliga - kutsutakse kohale mitmesuguseid üleloomulikke olendeid ning püütakse saavutada nende kaitset ja eestkostet kogukonda puudutavates elulistes küsimustes. Lisaks peab kogu peo käik näitama seda, et inimesed tunnevad jumaluste poolt kehtestatud maailmakorda ja reegleid. Kui shamaanirituaali puhul esineb pärimuslik kontroll sageli nn. õige tee otsinguna, mille käigus shamaan surub publiku abil oma ekstaatilise kogemuse ning improvisatsioonilise meisterlikkuse traditsioonilisse vormi, sundides ühtlasi pealtvaatajaid rituaaliga mõttes kaasa minema ning kontrollima või värskendama oma usundi- ja rahvaluulealaseid teadmisi, siis karupeietel toimib samasugune vastastikkune teadmiste kontroll kolmnurgas publik, lauljad, peoperemees (karu tapja). 